\title{
Release from latent inhibition with delayed testing
}

\author{
PHILIPP J. KRAEMER, CHRISTOPHER K. RANDALL, and TIMOTHY J. CARBARY \\ University of Kentucky, Lexington, Kentucky
}

\begin{abstract}
A conditioned emotional response procedure was used to study the interactive effects of stimulus preexposure and retention interval in rats. In Experiment 1, the subjects were conditioned by presenting a light CS paired with mild footshock as the US. Half of the subjects were given nonreinforced preexposure to the CS, and the others were not. Separate preexposed and nonpreexposed groups were then tested 1, 7, or 21 days after conditioning. Suppression of ongoing activity was used to assess the degree of conditioned fear. Latent inhibition was found at the 1-day retention interval; the preexposed subjects displayed less conditioned fear than did the nonpreexposed subjects. In contrast, equally strong conditioned fear was expressed by the preexposed and the nonpreexposed groups tested after the 7 - and the 21-day retention intervals. These results indicate a release from latent inhibition similar to that obtained with conditioned taste aversions (Kraemer \& Roberts, 1984). The results of Experiment 2 suggest that retention-interval-induced increases in sensitization, pseudoconditioning, or neophobia cannot account for the release from latent inhibition effect obtained in Experiment 1. The implications of these findings for a retrievaloriented view of latent inhibition are discussed.
\end{abstract}

Nonreinforced preexposure to a CS, or to a stimulus similar to the CS, decreases the subsequent strength of conditioned responding expressed to the CS (Dawley, 1979; Lubow, 1973; Mackintosh, 1983). This wellestablished phenomenon, termed latent inhibition (LN), has appeared across a wide range of CSs, USs, and procedures (Albert \& Ayres, 1989; Elkins, 1973; Lubow, Markman, \& Allen, 1968; Lubow \& Moore, 1959; Reiss $\&$ Wagner, 1972). A variety of theoretical proposals have been proffered to explain LI (DeVietti et al., 1987; Kalat, 1977; Lubow, Schnur, \& Rifkin, 1976; Mackintosh, 1975; Pearce \& Hall, 1980; Wagner, 1981). Although different in detail, the theoretical alternatives share the implicit assumption that $\mathrm{LI}$ corresponds to an acquisition failure. Accordingly, it has been assumed that, with stimulus preexposure, the subject fails to learn as much or as well as he/she does without it. There is more recent evidence, however, that challenges the learning deficit view of LI. Several experiments have shown that stimulus preexposure does not necessarily disrupt acquisition of the conditioning episode. This evidence includes (1) demonstrations that postacquisition reminder treatments can alleviate the performance deficit otherwise obtained with stimulus preexposure (Kasprow, Catterson, Schachtman, \& Miller, 1984) and (2) a release from LI effect associated with delayed testing (Kraemer \& Roberts, 1984).

The release from LI effect has appeared with the conditioned taste aversion (CTA) procedure. It is well estab-

This project was supported in part by BRSG SO7 RRO7114-21 awarded to the first author. Correspondence should be addressed to Philipp J. Kraemer, Department of Psychology, University of Kentucky, Lexington, KY 40506-0044. lished that prior nonreinforced experience with a flavor can attenuate the expressed strength of a CTA to either that same flavor or some similar flavor (Dawley, 1979; Domjan, 1972; Kalat \& Rozin, 1973; Revusky \& Bedarf, 1967; Siegel, 1974). It has been shown recently, however, that the preexposure effect can dissipate when testing is delayed by a week or more; preexposed and nonpreexposed subjects sometimes express equally strong taste aversions when tested after prolonged retention intervals (Kraemer, Hoffmann, \& Spear, 1988; Kraemer \& Ossenkopp, 1986; Kraemer \& Roberts, 1984; Strohen, Bakner, Nordeen, \& Riccio, 1990). Both the reminderinduced recovery of conditioned responding (e.g., Kasprow et al., 1984) and the release from LI effect obtained with delayed testing are incompatible with the assumption that $L I$ constitutes a learning deficit. If stimulus preexposure disrupts acquisition, then how can subjects come to behave as if no learning deficit has occurred? These effects suggest instead that LI might involve a retrieval deficit (Miller, Kasprow, \& Schachtman, 1986; Spear, 1981).

Given the provocative nature of the release from LI effect and its theoretical significance, it is imperative that the reliability and generality of the effect be assessed. Perhaps release from $\mathrm{LI}$ is an unreliable effect that appears only with CTA, which would minimize its theoretical significance. Conversely, a release from LI may be potentially available with any procedure that can produce LI. We now report two experiments indicating that, indeed, the effect is not limited to taste aversion learning. Rats were conditioned with a light CS paired with mild footshock as the US; the strength of acquired fear was measured by the degree to which general activity was sup- 
pressed by the light. Prior to conditioning, half of the subjects were preexposed to the light. Separate groups of preexposed and nonpreexposed subjects were tested after different retention intervals, and, consistent with results from CTA experiments, LI dissipated with delayed testing.

\section{EXPERIMENT 1}

\section{Method}

Subjects. The subjects were 54 Sprague-Dawley-derived adult rats (60-90 days of age). Each subject was housed individually in stainless steel hanging cages. All animals were located in the same climate-controlled vivarium, which operated on a 16:8-h light:dark cycle; all testing occurred during the light phase $(16 \mathrm{~h})$ of the cycle. Each subject had free access to food and water. All animal maintenance procedures and test protocols were reviewed by the University of Kentucky Animal Research Care and Use Committee.

Apparatus. The test box was housed in an animal isolation chamber, with the inside dimensions measuring $64 \mathrm{~cm}$ (length) $\times 48 \mathrm{~cm}$ (width) $\times 64 \mathrm{~cm}$ (height). The chamber was equipped with a sidemounted fan that provided ventilation as well as constant background noise. A 7.5-W lamp, which served as the CS, was attached to the ceiling of the chamber. A 2.1-W lamp was placed on the chamber floor, along the wall that contained the fan; it provided constant dim background illumination throughout the chamber.

An ultrasonic activity-monitoring device, modeled after that described by Moye and Rudy (1985), was mounted on the front wall of the isolation chamber, opposite to the wall containing the fan. The device consisted of a circular transmitter and a receiver, each $2.4 \mathrm{~cm}$ in diameter, which were mounted $10 \mathrm{~cm}$ above the chamber floor and spaced $5 \mathrm{~cm}$ apart. Air-current disturbances, resulting from movement of an animal within the chamber, were detected as frequency discrepancies by the receiver and initiated closure of an electromechanical relay; the degree of movement of an animal within the chamber was positively correlated with the number of relay closures. The sensitivity of the device was tuned by the procedure described by Moye and Rudy (1985). A 36-cm Plexiglas frame, containing stainless steel rods, was placed on the floor of the isolation chamber, centered under the ceiling light. The grids were attached to a Lafayette Instruments scrambled shock generator (Model 82404-SS). Fresh pine shavings were placed beneath the grids. A floorless Plexiglas box, painted flat gray, was placed directly on the grids. It measured $36 \mathrm{~cm}$ (length) $\times 25 \mathrm{~cm}$ (width) $\times 25 \mathrm{~cm}$ (height) and contained two holes placed in the front wall, which allowed the transmitter and receiver to extend slightly inside the box. The box was covered by a transparent Plexiglas lid. A three-chamber gray Plexiglas partition was placed inside the box during the preexposure and conditioning phases. This unit divided the test box into three equal-size chambers, each measuring $24 \mathrm{~cm}$ (length) $\times 11 \mathrm{~cm}$ (width) $\times 25 \mathrm{~cm}$ (height). All stimulus events and response recording were controlled by a Commodore 64 computer and a locally constructed interface, which was attached to appropriate electromechanical relay equipment.

Procedure. The subjects were randomly assigned to the six groups $(n=9)$. All subjects were exposed to the test context prior to the start of the experiment. This exposure consisted of a single $30-\mathrm{min}$ placement in the conditioning apparatus, presented $24 \mathrm{~h}$ before the CS-preexposure phase of the experiment. Three of the groups were preexposed to the CS prior to conditioning, and the other three groups were not. The nonpreexposed groups received no treatment in addition to that presented during the conditioning phase. The CS consisted of a 15-sec presentation of the ceiling light. The subjects were preexposed and conditioned in sets of 3 , but were tested individually. Each preexposure session consisted of 20 presentations of the CS, separated by a variable time (VT) 90-sec intertrial interval. During conditioning, a $0.75-\mathrm{sec} 1-\mathrm{mA}$ scrambled footshock occurred at the termination of each CS. Each subject received 12 light-shock pairings, temporally arranged according to a VT 120-sec schedule. A 1-h interval, during which the subject was in the home cage, separated the preexposure and conditioning phases. Testing occurred 1, 7, or 21 days after conditioning, depending on the group to which the subject was assigned. The animals spent the retention interval in their home cages. Each subject received a 6-min test period, which was divided into six 1-min intervals. Each test interval was correlated with one of two stimulus events: light (CS) or no light. All subjects were tested with the following sequence: no light - no light - light - no light - no light - light. The total number of activity counts were recorded for each of the six intervals, with each relay closure defined as one activity count.

\section{Results and Discussion}

All statistical analyses were evaluated at a .05 level of significance. Mean activity counts for the six groups during each of the six 1-min test intervals are presented in panel A of Figure 1. The extent to which the subjects expressed fear of the light is indicated by the magnitude of the decrement in activity between Intervals 2 and 3 and between Intervals 5 and 6 . Although all groups showed some decrement in activity during light presentations, the size of the decrement varied across groups. The most striking aspect of this effect is that the magnitude of the decrement seen in the preexposed subjects increased substantially as retention interval increased, to the point that the large difference in the magnitude of the decrement between the preexposed and the nonpreexposed subjects tested at the 1-day retention interval was absent after 7 and 21 days. It can also be seen that the relative size of the light-induced decrement in activity among the preexposed subjects increased as the retention interval lengthened; this effect is apparent at both of the light presentations (Intervals 3 and 6).

Before presenting statistical confirmation of these conclusions, there are several aspects of the activity-count data that need to be emphasized. First, baseline differences in general activity (activity counts during the nolight intervals) did appear across groups. Particularly salient are the differences between the preexposed and the nonpreexposed subjects, most notable at the 1-day retention interval. Second, the nonpreexposed subjects tended not to recover the loss in activity that accompanied the first presentation of the light (Interval 3); this is especially pronounced at the 1- and 7-day retention intervals. In contrast, the preexposed subjects showed substantial recovery; activity levels within each of the preexposed groups appear to be about the same during Intervals 2 and 5 . Third, overall activity declined regularly with retention interval in the preexposed subjects, but this same monotonic trend did not emerge among the nonpreexposed subjects.

To compare levels of fear expressed by the six groups, we analyzed suppression ratios. The suppression ratio compares each subject's activity during a light interval with its activity during the immediately preceding no-light interval. Suppression ratios have typically been used to 

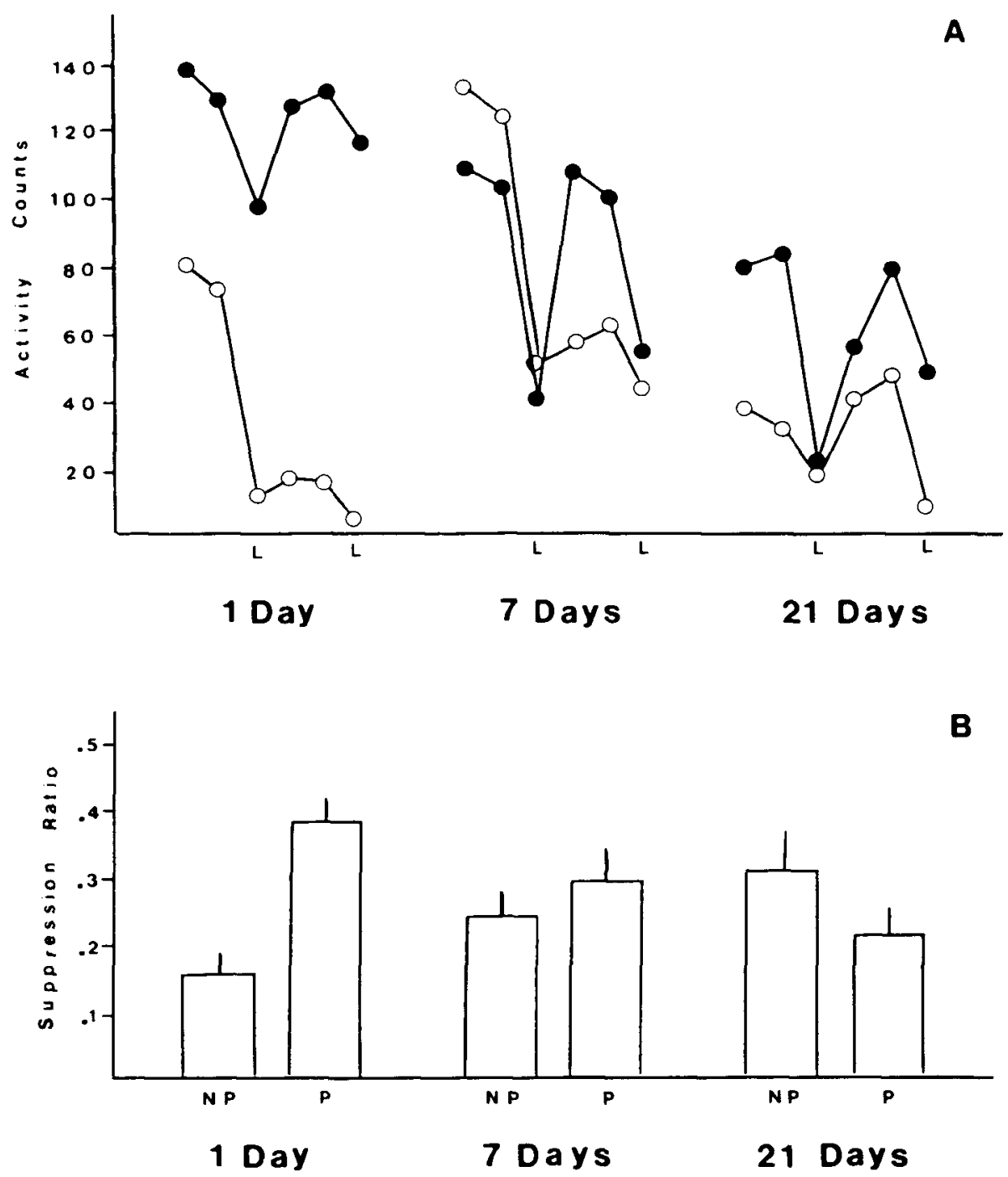

Figure 1. Mean activity counts during each of the six test intervals (panel $A$ ) and mean suppression ratios (paned B) for preexposed (Group P and open circles) and nonpreexposed groups (Group NP and rilled circles) tested at 1-, 7-, and 21-day retention intervals. The $L$ refers to test intervals that included the light.

evaluate conditioned fear, and they are appropriate when baseline differences exist, although they must then be interpreted with caution (LoLordo, 1979). Given the pronounced reduction in activity expressed by the nonpreexposed subjects after the first light interval, it is inappropriate to compare suppression ratios for Intervals 5 and 6 or to rely on a combined measure that summates across the two light presentations. The low baseline activity levels expressed by the nonpreexposed subjects after the first light presentation could have made it impossible for these subjects to register any further decrease in activity during the second light presentation, which would inaccurately reflect a low level of fear. Thus, the primary score by which we compared the six groups was the suppression ratio for the first light presentation, which involved Intervals 2 and 3.

Mean suppression ratios for each of the six groups appear in panel B of Figure 1. These suppression ratios were calculated according to the following formula: activity counts during Interval $3 /$ sum of the activity counts during Intervals 2 and 3 . It can be seen that the preexposed subjects expressed less fear of the light than did the nonpreexposed subjects at the 1-day retention interval, as indicated by the higher suppression ratios for the preexposed group. At the 7-and 21-day retention intervals, however, levels of fear were nearly equal in the preexposed and nonpreexposed subjects, as indicated by the comparable suppression ratios for the two groups at each retention 
interval. Another way to describe these trends is to note that fear increased with retention interval among the preexposed subjects and decreased with retention interval among the nonpreexposed subjects. These conclusions were confirmed by statistical analyses. A group (preexposure vs. no preexposure) $\times$ retention interval $(1,7$, or 21 days) ANOVA of the suppression ratios indicated a significant interaction between preexposure experience and retention interval $[F(2,47)=3.14]$. Individual group comparisons (Newman-Keuls test) further revealed that suppression ratios were significantly higher in the preexposed subjects than in the nonpreexposed subjects at the 1-day retention interval, but suppression ratios were equivalent in the preexposed and nonpreexposed groups at both the 7- and 21-day retention intervals. Additional group comparisons indicated that suppression ratios significantly declined among the preexposed subjects and significantly increased among the nonpreexposed subjects over the three retention intervals. This pattern of results suggests LI evident at the 1-day retention interval was not evident at the 7- and 21-day retention intervals, and that acquired fear of the light increased with retention interval among the preexposed subjects and decreased with retention interval among the nonpreexposed subjects; however, the latter conclusion needs to be tempered by the low baseline activity found among the nonpreexposed subjects tested after 21 days.

\section{EXPERIMENT 2}

To demonstrate release from LI and to argue that LI constitutes a retrieval deficit, alternative nonassociative explanations of retention interval effects of the type found in Experiment 1 need to be excluded. The design of Experiment 1 , however, did not contain the appropriate control groups for that purpose. Experiment 2, therefore, has been added to meet two critical concerns. The first involves the theoretical claim that $\mathrm{LI}$ constitutes a retrieval failure. This position presupposes that $C S$ preexposure does not prevent the subject from representing the CS-US relation, but instead disrupts subsequent retrieval of that representation. To substantiate that claim, we must show that retention interval does not induce conditioned suppression in the absence of a CS-US relation-that is, we must show that the increased conditioned fear of the light expressed by preexposed subjects tested after an extended delay does not constitute some form of delay-induced sensitization or pseudoconditioning. The second concern is that there may be some form of unconditioned suppression to the light that habituates during preexposure and recovers over a delay period. This idea is related to the notion that neophobic reactions to the CS may increase directly with retention interval (Lubow, 1989).

Additional subjects were tested in order to address these issues. One group was preexposed to the light CS before receiving unpaired presentations of light and shock. Two other groups were not preexposed to the light; light and shock were then paired for one of these groups and un- paired for the other group. In addition, the amount of test context experience was equated across the three groups, so that all subjects received comparable handling and general experience in the test apparatus. Half of the subjects in each of the three groups were tested 1 day after conditioning, and the remaining subjects were tested after a 7-day retention interval. If the results of Experiment 1 reflect an actual release from LI, then enhanced suppression to the CS would not be expected in the groups tested in Experiment 2. Conversely, the appearance of such an effect would undermine the release from LI hypothesis of the results from Experiment 1.

\section{Method}

Forty-eight adult Sprague-Dawley rats were randomly assigned to three groups $(n=16)$. Each rat was given two training sessions, separated by $24 \mathrm{~h}$. The first session involved acclimation to the test context, which consisted of 30-min exposure to the test apparatus in the absence of the CS or US. The CS-preexposure phase commenced 24 h later. Group P-UP received 20 presentations of a 15 sec light, separated according to a VT 90 -sec schedule; Groups NP-P and NP-UP were placed in the text context for the same duration as was Group P-UP, but in the absence of light presentations. A 1-h interval, which the subject spent in the home cage, separated the preexposure phase from the conditioning phase. Conditioning consisted of 12 light presentations and 12 0.75-sec, 1-mA footshocks. Group NP-P received shocks at the end of each light presentation. Groups P-UP and NP-UP received 12 shocks, separated according to a VT 90 -sec interval, were returned to the home cage for $30 \mathrm{~min}$ and then returned to the test apparatus and given 12 light presentations, arranged according to a VT 90-sec schedule. We adopted this unpaired procedure because some of our other research has indicated that, with only 12 conditioning trials, randomly arranged lights and shocks can produce substantial conditioned excitation, and our objective was to minimize the degree to which the subjects in these groups perceived a positive correlation between the light and the shock. Half of the subjects in each of the three groups were tested $24 \mathrm{~h}$ after conditioning; the remaining subjects were tested after a 7 -day retention interval. The remaining procedural details followed those outlined in Experiment 1.

\section{Results and Discussion}

The mean activity counts during each of the six test intervals for the six groups tested in Experiment 2 appear in Figure 2. Although some fluctuations in activity occurred across the six test intervals in all groups, only the nonpreexposed groups given the light and shock in a paired fashion demonstrated a substantial decrement in activity during the light presentations. This conclusion can be more clearly appreciated by observing the suppression ratios presented in panel $B$ of Figure 2, which contrast activity during Intervals 2 and 3, calculated as in Experiment 1 . These scores were subjected to a two-factor ANOVA, with the factors consisting of conditioning experience (nonpreexposed and CS-US paired, preexposed and CS-US unpaired, or nonpreexposed and CS-US unpaired) and retention interval ( 1 or 7 days). The analysis yielded a significant main effect of conditioning experience $[F(2,41)=20.4]$, but neither the main effect of retention interval nor the interaction between conditioning experience and retention interval reached significance. Individual group comparisons (Newman-Keuls test) in- 

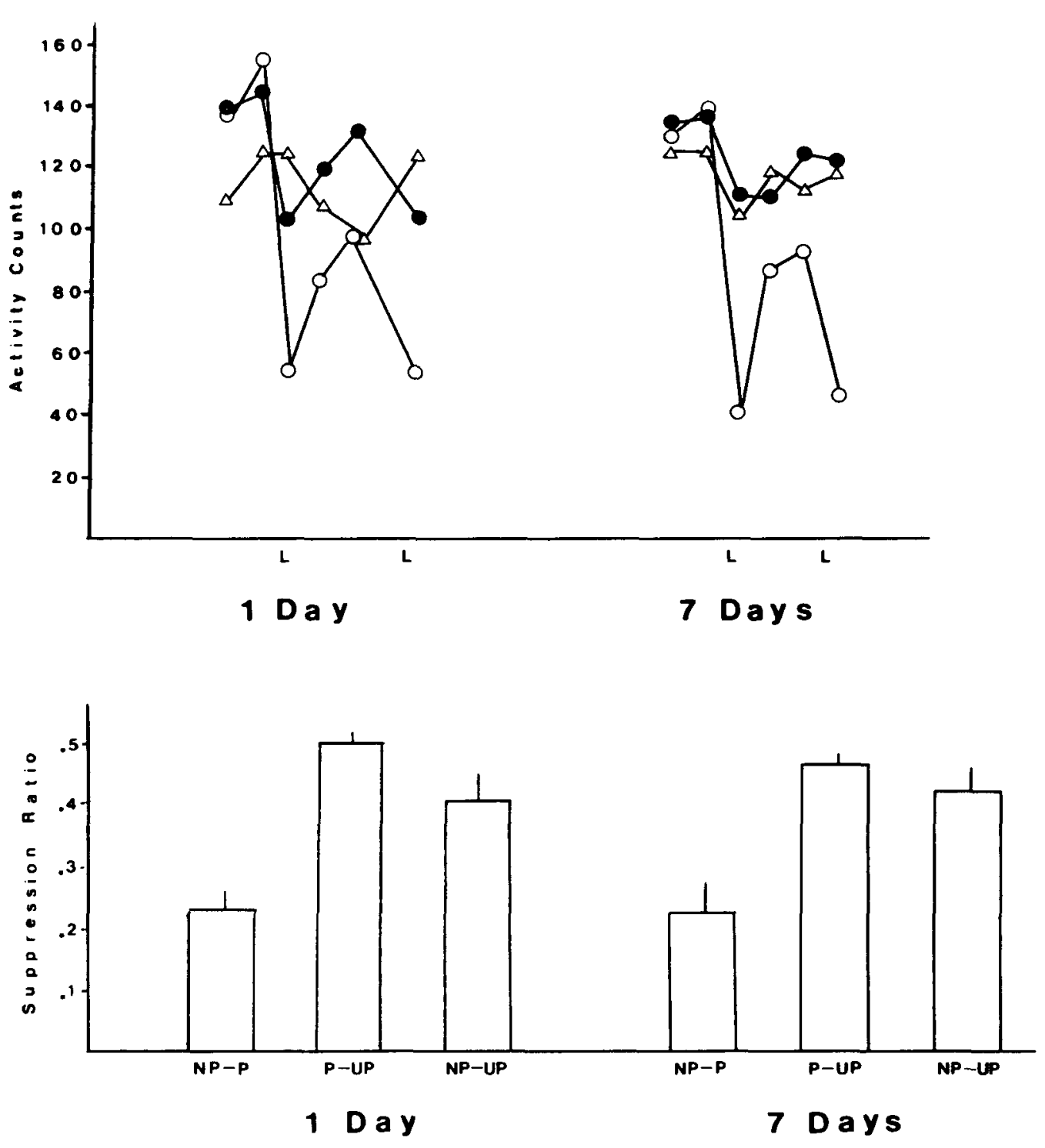

Figure 2. Mean activity counts during each of the six test intervals (panel A) and mean suppression ratios (panel B) for subjects tested in Experiment 2 after either a 1- or 7-day retention interval. Nonpreexposed groups were given the CS and US paired (Group NP-P and open circles) or unpaired (Group NP-UP and filled circles), and the preexposed group received the CS and US unpaired (Group P-UP and open triangles). The L refers to test intervals that included the light.

dicated that suppression ratios of Group NP-P differed significantly from the corresponding scores of Groups NP-UP and P-UP at both retention intervals, but suppression ratios for Groups NP-UP and P-UP did not differ significantly at either retention interval.

There are two other important observations to be made. One is that baseline activity (activity counts during Interval 2) for Group NP-UP did not differ at the two retention intervals, and the other is that these subjects showed substantial recovery in activity after the first light presen- tation at both retention intervals. This pattern of performance contrasts sharply with that of a comparable group of subjects tested in Experiment 1, which can be discerned by comparing the A panels of Figures 1 and 2 . Possible implications of this contrast will be discussed later.

The results indicate that exposure to noncorrelated presentations of a light and shock did not produce conditioned fear of the light and that this trend did not change over a 7-day retention interval. Thus, sensitization, pseudoconditioning, and neophobia are not apparent at either 
retention interval, which strengthens the claim that the results of Experiment 1 be viewed as an actual release from LI.

\section{GENERAL DISCUSSION}

The results of Experiment 1 indicate that the magnitude of conditioned fear expressed to a light CS, as indexed by suppression of ongoing activity, was reduced by prior nonreinforced exposure to the light, but only when testing occurred 1 day after conditioning. When testing was delayed by either 7 or 21 days, the level of suppression was comparable for the preexposed and nonpreexposed groups. Equally important, the results of Experiment 2 indicate that neither the preexposed nor the nonpreexposed subjects given unpaired presentations of light and shock expressed significant fear of the light after either 1- or 7-day retention intervals, which suggests that sensitization, pseudoconditioning, and neophobia do not appear to increase over a test delay in our procedure. Thus, we conclude that LI, which was apparent when testing occurred soon after conditioning, dissipated over a retention interval of 7 or more days. This conclusion is based both on a comparison of fear expressed by the preexposed and nonpreexposed groups at the three retention intervals and on the significant increase in fear noted among the preexposed subjects tested after 7 or 21 days.

There is another interesting feature of the results that is pertinent to an analysis of LI. In Experiment 1, the nonpreexposed subjects expressed substantially lower levels of baseline activity than was apparent in the preexposed subjects, and baseline activity declined as retention interval increased for both the preexposed and the nonpreexposed subjects. One interpretation of these effects is that conditioned fear of the test context was itself reduced by CS preexposure. In Experiment 1, the preexposed subjects were not only given nonreinforced exposure to the CS, but, by virtue of that experience, were also given nonreinforced exposure to the test context. Although shock was contiguous with light presentations, there is abundant empirical evidence and compelling theoretical arguments to suggest that some conditioned fear could have accrued to the test context (Miller \& Schachtman, 1985; Rescorla \& Wagner, 1972; Schachtman, Brown, Gordon, Catterson, \& Miller, 1987). Thus, perhaps the preexposed subjects in Experiment 1 expressed less context fear than did the nonpreexposed subjects due to their having had more nonreinforced exposure to the test context. The absence of baseline differences between the CS-preexposed and CS-nonpreexposed groups in Experiment 2, in which nonreinforced exposure to contextual cues was equated across groups, is consistent with this interpretation. Furthermore, the systematic decrease in baseline activity over the three retention intervals shown by the preexposed subjects in Experiment 1 could also be interpreted as a release from LI associated with fear of the context. The unfortunate anomaly, for which we have no adequate explanation, is the nonmonotonic change in baseline activity over retention interval found among the nonpreexposed subjects tested in Experiment 1; the nonpreexposed subjects tested after 7 days expressed higher baseline activity than did the nonpreexposed subjects tested after 1 or 21 days.

The important contribution of this study is that it establishes that the release from LI effect is not limited to the CTA procedure. Preexposure-induced attenuation of a conditioned emotional response, involving a peripheral CS and exteroceptive US, also seems to dissipate with delayed testing. This finding suggests that release from LI may constitute a general learning phenomenon, not one limited to taste aversion learning. It is also important to emphasize that the release from LI obtained here involved primary preexposure (nonreinforced experience with the CS itself), as opposed to generalized preexposure (nonreinforced experience with a stimulus similar to the $C S$ ). Release from LI with the CTA procedure has been found more reliably with generalized preexposure (Kraemer \& Ossenkopp, 1986; Kraemer \& Roberts, 1984), although release from LI with primary preexposure has been demonstrated (Kraemer, Hoffmann, \& Spear, 1988; Kraemer \& Roberts, 1984; Strohen et al., 1990).

If indeed the release from LI effect is a reliable phenomenon, then its implications need to be acknowledged. The fact that stimulus preexposure can exert an effect that dissipates with delayed testing, or can be eliminated with a reinstatement procedure (Kasprow et al., 1984), suggests that the locus of the preexposure effect is during retrieval, rather than the initial storage of information about the conditioning episode (Miller et al., 1986). This conclusion challenges the well-accepted assumption that prior experience with a stimulus reduces what can be subsequently learned about that stimulus, which is an assumption inherent in most theories of conditioning (Daly \& Daly, 1982; Grossberg, 1982; Holyoak, Koh, \& Nisbett, 1989; Mackintosh, 1975; Pearce \& Hall, 1980; Wagner, 1981 ). Given the provocative nature of the release from LI effect, it seems prudent for other investigators to further test its reliability. If such tests continue to confirm that delayed testing or reinstatement manipulations can eliminate performance deficits associated with stimulus preexposure, then a major change in the theoretical view of LI will be necessary. In general, perhaps Spear's (1981) contention that many of the phenomena typically attributed to the acquisition process are instead based on retrieval processes may be correct. This proposition now has some empirical support for several phenomena, including overshadowing (Kasprow, Cacheiro, Balaz, \& Miller, 1982; Kaufman \& Bolles, 1981; Kraemer, Lariviere, \& Spear, 1988; Matzel, Schachtman, \& Miller, 1985), blocking (Balaz, Gutsin, Cacheiro, \& Miller, 1982), extinction (Bouton, 1991), and LI.

\section{REFERENCES}

Albert, M., \& Ayres, J. J. B. (1989). With number of preexposures constant latent inhibition increases with preexposure CS duration or total CS exposure. Leaming \& Motivation, 20, 278-294.

Balaz, M. A., Gutsin, P., Cacheiro, H., \& Miller, R. R. (1982). Blocking as a retrieval failure: Reactivation of associations to a blocked stimulus. Quarterly Journal of Experimental Psychology, 34B, 99-113. 
Bouton, M. E. (1991). Context and retrieval in extinction and in other examples of interference in simple associative learning. In $\mathbf{L}$. W. Dachowski \& C. F. Flaherty (Eds.), Current topics in animal learning: Brain, emotion and cognition (pp. 25-53). Hillsdale, NJ: Erlbaum.

DAlY, H. B., DALY, J. T. (1982). A mathematical model of reward and aversive nonreward: Its applicability to over 30 appetitive learning situations. Journal of Experimental Psychology: General, 111, $441-480$.

DAWLEY, J. M. (1979). Generalization of the CS-preexposure effect transfers to taste aversion learning. Animal Learning \& Behavior, 7, 23-24.

DeViett, T. L., BAuste, R. L., Nutt, G., OWen, V., BArret, K. D., 2 Petree, A. D. (1987). Latent inhibition: A trace conditioning phenomenon? Learning \& Motivation, 18, 185-201.

DOMJAN, M. (1972). CS preexposure in taste-aversion learning: Effects of deprivation and preexposure duration. Learning \& Motivation, 3 , 389-402.

ElKINS, R. L. (1973). Attenuation of drug-induced bait shyness to a palatable solution as an increasing function of its availability prior to conditioning. Behavioral Biology, 9, 221-226.

Grossberg, S. (1982). Processing of expected and unexpected events during conditioning and attention: A psychophysiological theory. Psychological Review, 89, 529-572.

HolyoAk, K. J., КоH, K., NisBetT, R. E. (1989). A theory of conditioning: Inductive learning within rule-based default hierarchies. Psychological Review, 96, 315-340.

KALAT, J. W. (1977). Status of "learned safety" or "learned noncorrelation" as a mechanism in taste aversion learning. In L. M. Barker, M. R. Best, \& M. Domjan (Eds.), Learning mechanisms in food selection (pp. 273-293). Waco, TX: Baylor University Press.

Kalat, J. W., Rozin, P. (1973). "Learned safety" as a mechanism in long-delay taste aversion learning in rats. Journal of Comparative \& Physiological Psychology, 83, 198-207.

Kasprow, W. J., Cacheiro, H., Balaz, M. A., \& Mllegr, R. R. (1982). Reminder-induced recovery of associations to an overshadowed stimulus. Learning \& Motivation, 13, 155-166.

Kasprow, W. J., Catterson, D., Schachtman, T. R., Miller, R. R. (1984). Attenuation of latent inhibition by postacquisition reminder. Quarterly Jourmal of Experimental Psychology, 36B, 53-63.

KAUfman, M. A., Bolles, R. C. (1981). A nonassociative aspect of overshadowing. Bulletin of the Psychonomic Society, 18, 318-320.

Kraemer, P. J., HoffmanN, H., \& SPear, N. E. (1988). Attenuation of the CS-preexposure effect after a retention interval in preweanling rats. Animal Learning \& Behavior, 16, 185-190.

Kraemer, P. J., Lariviere, N. A., Spear, N. E. (1988). Expression of a taste aversion conditioned with an odor-taste compound: Overshadowing is relatively weak in weanlings and decreases over a retention interval in adults. Animal Learning \& Behavior, 16, 164-168.

Kraemer, P. J., Ossenkopp, K. P. (1986). The effects of flavor preexposure and test interval on conditioned taste aversions in rats. Bulletin of the Psychonomic Society, 24, 219-221.

Kraemer, P. J., Roberts, W. A. (1984). The influence of flavor preexposure and test interval on conditioned taste aversions in the rat. Learning \& Motivation, 15, 259-278.

LoLordo, V. M. (1979). Classical conditioning: The Pavlovian perspective. In M. E. Bitterman, V. M. LoLordo, J. B. Overmier, \& M. E. Rashotte (Eds.), Animal learning (pp. 25-60). New York: Plenum.

Lubow, R. E. (1973). Latent inhibition. Psychological Review, 79, 398-407.

Lubow, R. E. (1989). Latent inhibition and conditioned attention theory. New York: Cambridge University Press.
Lubow, R. E., Markman, R. E., Allen, J. (1968). Latent inhibition and classical conditioning of the rabbit pinna response. Joumal of Compararive \& Physiological Psychology, 66, 688-694.

Lubow, R. E., Moore, A. U. (1959). Latent inhibition: The effect of nonreinforced pre-exposure to the conditioned stimulus. Joumal of Comparative \& Physiological Psychology, 52, 415-419.

Lubow, R. E., SchNuR, P., Rifin, B. (1976). Latent inhibition and conditioned attention theory. Joumal of Experimental Psychology: Animal Behavior Processes, 2, 163-174.

MACKIntosh, N. J. (1975). A theory of attention: Variations in the associability of stimuli with reinforcement. Psychological Review, 82. 276-298.

MaCKIN TOSH, N. J. (1983). Conditioning and associative learning. Oxford: Oxford University Press.

Matzel, L. D., Schachtman, T. R., Miller, R. R. (1985). Recovery of an overshadowed association achieved by extinction of the overshadowing stimulus. Learning \& Motivation, 16, 398-412.

Miller, R. R., Kasprow, W. J., * Schachtman, T. R. (1986). Retrieval variability: Sources and consequences. American Journal of Psychology, 99, 145-218.

Miller, R. R., Schachtman, T. R. (1985). Conditioning context as an associative baseline: Implications for response generation and the nature of conditioned inhibition. In R. R. Miller \& N. E. Spear (Eds.), Information processing in animals: Conditioned inhibition (pp. 51-88). Hillsdale, NJ: Erlbaum.

MoYe, T. B., RUDY, J. W. (1985). Ontogenesis of learning: VI. Learned and unlearned responses to visual stimulation in the infant hooded rat. Developmental Psychobiology, 18, 395-409.

Pearce, J. M., Hall, G. (1980). A model for Pavlovian learning: Variations in the effectiveness of conditioned but not of unconditioned stimuli. Psychological Review, 87, 532-552.

Reiss, S., WAGNer, A. R. (1972). CS habituation produces a "latent inhibition" effect but no active "conditioned inhibition." Leaming \& Motivation, 3, 237-245.

Rescorla, R. A., Wagner, A. R. (1972). A theory of Pavlovian conditioning: Variations in the effectiveness of reinforcement and nonreinforcement. In A. H. Black \& W. F. Prokasy (Eds.), Classical conditioning: II. Current research and theory (pp. 64-99). New York: Appleton-Century-Crofts.

RevUSKY, S. H., BEDARF, E. W. (1967). Association of illness with prior ingestion of novel foods. Science, 155, 219-220.

Schachtman, T. R., Brown, A. M., Gordon, E. L., Catterson, D. A., MiLler, R. R. (1987). Mechanisms underlying retarded emergence of conditioned responding following inhibitory training Evidence for the comparator hypothesis. Joumal of Experimental Psychology: Animal Behavior Processes, 13, 310-322.

Siegel, S. (1974). Flavor preexposure and "leamed safety." Journal of Comparative \& Physiological Psychology, 87, 1073-1082.

SPEAR, N. E. (1981). Extending the domain of memory retrieval. In N. E. Spear \& R. R. Miller (Eds.), Information processing in animals: Memory mechanisms (pp. 341-378). Hillsdale, NJ: Erlbaum.

Strohen, K., Bakner, L., Nordeen, M., \&iccio, D. C. (1990, May). Post-conditioning recovery from the latent inhibition effect in conditioned taste aversion. Paper presented at the annual meeting of the Midwestern Psychological Association, Chicago, IL.

WAGNER, A. R. (1981). SOP: A model of automatic memory processing in animal behavior. In N. E. Spear \& R. R. Miller (Eds.), Information processing in animals: Memory mechanisms (pp. 5-47). Hillsdale, NJ: Erlbaum.

(Manuscript received June 19, 1990; revision accepted for publication January 28, 1991.) 